\title{
Improvement of Power Efficiency in Phosphorescent White Organic Light-Emitting Diodes Using p-Doped Hole Transport Layer
}

\author{
Hyunkoo Lee, Jun Young Kim, and Changhee Lee \\ Department of Electrical Engineering and Computer Science, Inter-University Semiconductor Research Center, \\ Seoul National University, 1 Gwanak-ro, Gwanak-gu, Seoul 151-744, Republic of Korea \\ Correspondence should be addressed to Changhee Lee, chlee7@snu.ac.kr
}

Received 14 July 2011; Revised 12 October 2011; Accepted 13 October 2011

Academic Editor: Raghu N. Bhattacharya

Copyright (๑) 2012 Hyunkoo Lee et al. This is an open access article distributed under the Creative Commons Attribution License, which permits unrestricted use, distribution, and reproduction in any medium, provided the original work is properly cited.

We investigated the optical and electrical properties of molybdenum trioxide- $\left(\mathrm{MoO}_{3}-\right)$ doped (1,1-bis[(di-4tolylamino)phenyl]cyclohexane) (TAPC) films with different doping concentrations. Based on our results, we have fabricated white organic light emitting diodes (WOLEDs) with multi-emitting layer structures that consist of 1,3-bis(9-carbazolyl)benzene as a host and three phosphorescent dopants: iridium(III) bis[4,6-difluorophenyl]-pyridinato-N, $\left.\mathrm{C}^{2^{\prime}}\right]$ picolinate as a blue dopant, bis(2-phenylbenxothiozolato-N, $\mathrm{C}^{2^{\prime}}$ )iridium(III) (acetylacetonate) as an orange dopant, and bis(1-phenylisoquinoline) (acetylacetonate) iridium(III) as a red dopant. We improved the power efficiency and decreased driving voltage of WOLEDs by employing a $\mathrm{MoO}_{3}$-doped TAPC layer as a hole transport layer. The $\mathrm{MoO}_{3}$-doped TAPC layer lowers the driving voltage by about $1.2 \mathrm{~V}$ and increases the power efficiency from $6.2 \mathrm{~lm} \cdot \mathrm{W}^{-1}$ to $7.9 \mathrm{~lm} \cdot \mathrm{W}^{-1}$ at $1,000 \mathrm{~cd} \cdot \mathrm{m}^{-2}$, an approximately $27.4 \%$ increase. Furthermore, the WOLED has a high color-rendering index, which is about 86 with the Commission Internationale de l'Eclairage 1931 chromatic coordinates of $(0.4303,0.3893)$ and correlated color temperature of $3008 \mathrm{~K}$.

\section{Introduction}

White organic light-emitting diodes (WOLEDs) have attracted great attention due to their applications in fullcolor displays, backlights for liquid crystal displays (LCDs), and solid-state lightings [1-5]. Because WOLEDs have many merits, such as high efficiency, high color-rendering index (CRI) and flexibility of design, they are studied intensively as lighting sources. The improvement in power efficiency is especially important in lighting sources because energy saving is currently a crucial issue. To enhance the power efficiency of WOLEDs, one needs to increase the quantum efficiency and decrease the driving voltage of the device.

To achieve high quantum efficiency in phosphorescent OLEDs, charges and triplet excitons must be confined to the emission region of a device. Therefore, the hole transport material and electron transport material should have shallow lowest-unoccupied-molecular-orbital (LUMO) and deep highest-occupied-molecular-orbital (HOMO) energy levels, respectively. In addition, they also have a higher triplet energy level than that of the emitting material. For example, a device with 1,1-bis[(di-4-tolylamino)phenyl]cyclohexane (TAPC) has much higher quantum efficiency than a device with other hole transport materials, such as $4,4^{\prime}$-bis [N(1-naphthyl)-N-phenylamino]biphenyl $(\alpha-\mathrm{NPD})$ and 4,4'bis[N-(p-tolyl)-N-phenylamino]biphenyl (TPD), due to its higher triplet energy level compared with other hole transport materials [6].

To decrease the driving voltage of OLEDs, the potential energy barrier between the electrode and the organic material should be reduced and the carrier transport material should have high electrical conductivity. Electrical doping such as p-doping and $\mathrm{n}$-doping can reduce the driving voltage of OLEDs because it decreases the contact resistance between the electrodes and organic materials as well as increases the electrical conductivity of organic materials 
[7]. Recently, transition metal oxides such as molybdenum trioxides $\left(\mathrm{MoO}_{3}\right)$ and tungsten trioxides $\left(\mathrm{WO}_{3}\right)$ have been widely used as p-dopants to enhance hole injection and transport in organic devices [8-13].

In this paper, we investigate the electrical and optical properties of $\mathrm{MoO}_{3}$-doped TAPC films with different doping concentrations. Based on these results, we fabricated trichromatic WOLEDs with red, orange, and blue emission layers. By employing an $\mathrm{MoO}_{3}$-doped TAPC layer as a hole transport layer (HTL), we improved the power efficiency and decreased the driving voltage of WOLEDs. In addition, the WOLEDs show a high CRI of about 86 with the Commission Internationale de l'Eclairage (CIE) 1931 chromatic coordinates of $(0.4303,0.3893)$ and correlated color temperature (CCT) of $3008 \mathrm{~K}$.

\section{Experimental}

2.1. Method. Films were grown on quartz glass and indiumtin oxide- (ITO-) precoated glass substrates for optical absorption spectra measurement and device fabrication, respectively. The substrates were cleaned with acetone and isopropyl alcohol and were rinsed with deionized water. All substrates were dried in an oven filled with nitrogen gas at $200^{\circ} \mathrm{C}$ for 30 minutes. After being dried, patterned ITO substrates were treated in ultraviolet ozone for 5 minutes. All layers were grown in succession by thermal evaporation without breaking vacuum. During the deposition of the doping layers, the deposition rates of both the host and guest materials were controlled with a quartz crystal oscillator and source shutters.

2.2. Measurement. Optical absorption spectra were measured using a UV/Vis spectrophotometer (BECKMAN DU70). The current-voltage-luminance characteristics were measured using a Keithley-236 source measurement unit and a Keithley 2000 multimeter. The luminance and efficiencies were calculated from photocurrent measurement data obtained with a calibrated Si photodiode (Hamamatsu S5227-1010BQ), a photomultiplier tube, and electroluminescence (EL) spectra data obtained using a spectroradiometer (Minolta CS-1000A). The CIE 1931 chromatic coordinates and CCT are also obtained using a spectroradiometer. The CRIs were calculated using the procedure defined by CIE [14]. The HOMO and LUMO energy levels of all materials used in this work were obtained from the references and the measured data by a photoelectron spectrometer (Hitachi AC2) and UV/Vis spectrophotometer.

\section{Results and Discussion}

3.1. Characteristics of $\mathrm{MoO}_{3}$-Doped TAPC Films. Figure 1 shows the optical absorption spectra of $\mathrm{MoO}_{3}$, undoped TAPC, and $\mathrm{MoO}_{3}$-doped TAPC films with different $\mathrm{MoO}_{3}$ concentrations. All film thicknesses are $100 \mathrm{~nm}$. The absorption spectrum of the undoped TAPC film shows an absorption peak at $310 \mathrm{~nm}$ and no absorption peaks between

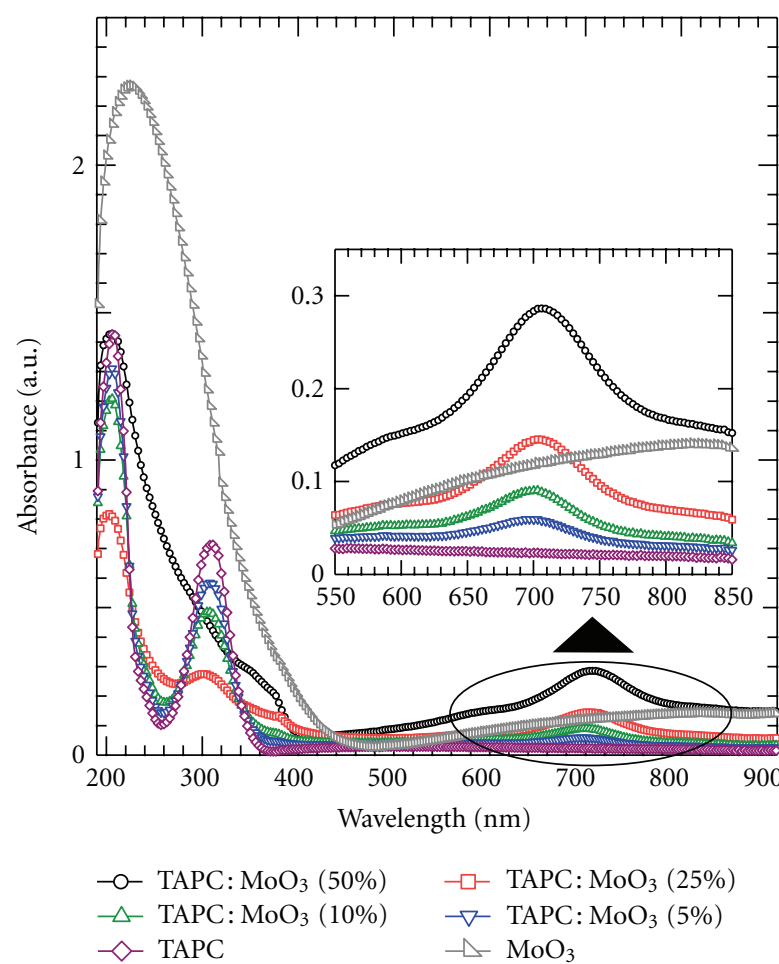

FIgURE 1: Optical absorption spectra of $\mathrm{MoO}_{3}$, undoped TAPC, and $\mathrm{MoO}_{3}$-doped TAPC films with different $\mathrm{MoO}_{3}$ concentrations. Inset: increase of CT complex absorption peak $(703 \mathrm{~nm})$ as the $\mathrm{MoO}_{3}$ concentration increases.

$400 \mathrm{~nm}$ and $900 \mathrm{~nm}$. However, the optical absorption spectrum of the $\mathrm{MoO}_{3}$-doped TAPC film shows an additional absorption peak at $703 \mathrm{~nm}$, and the intensity of this new peak increases as the doping concentration of the $\mathrm{MoO}_{3}$ increases, as shown in the inset of Figure 1. This new peak is absent in the optical absorption spectra of undoped TAPC and $\mathrm{MoO}_{3}$ films. This result is similar to other p-type doping results discussed in other literatures, and they explain that the new absorption peak is originated from the charge transfer (CT) complex between the hole transport material and dopant $[12,15,16]$. Therefore, the absorption peak at $703 \mathrm{~nm}$ in the $\mathrm{MoO}_{3}$-doped TAPC film indicates the formation of CT complexes between the TAPC and the $\mathrm{MoO}_{3}$, resulting in ptype doping of the TAPC.

To investigate the enhancement in hole injection and transport of the $\mathrm{MoO}_{3}$-doped TAPC layer, we fabricated hole-only devices with device structures composed of ITO/TAPC: $\mathrm{MoO}_{3}(x$ vol.\%, $100 \mathrm{~nm}) / \mathrm{Al}(100 \mathrm{~nm})$ and ITO/ $\mathrm{MoO}_{3}(5 \mathrm{~nm}) / \mathrm{TAPC}: \mathrm{MoO}_{3}(x$ vol. $\%, 100 \mathrm{~nm}) / \mathrm{MoO}_{3}$ $(5 \mathrm{~nm}) / \mathrm{Al}(100 \mathrm{~nm})$. The $\mathrm{MoO}_{3}$ layer $(5 \mathrm{~nm})$ can efficiently inject holes from electrode to organic layer so we can find that the cause of current increase is whether the enhancement of hole injection or hole transport of the $\mathrm{MoO}_{3}$-doped TAPC layer by comparing above two devices $[9,17]$. Figure 2(a) shows the current density-voltage $(J-$ $V)$ characteristics of the hole-only devices with different $\mathrm{MoO}_{3}$ concentrations. The devices with a $\mathrm{MoO}_{3}$-doped layer exhibit dramatically enhanced hole injection and transport 


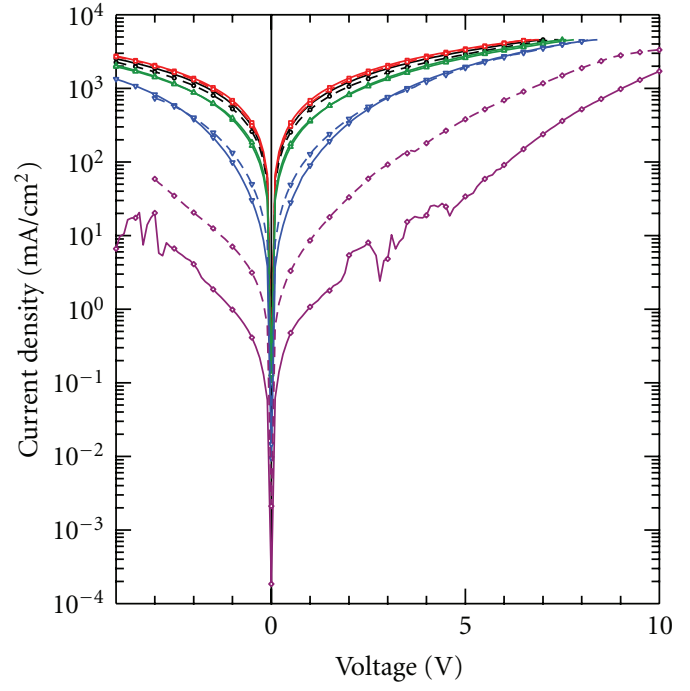

$$
\begin{aligned}
& \text { ○- - - TAPC: } \mathrm{MoO}_{3}(50 \%) \\
& \neg--\square-\text { TAPC: } \mathrm{MoO}_{3}(25 \%) \\
& \triangle--\triangle-\text { TAPC: } \mathrm{MoO}_{3}(10 \%) \\
& \rightarrow--\nabla-\text { TAPC: } \mathrm{MoO}_{3}(5 \%) \\
& \diamond-\diamond-\text { TAPC }
\end{aligned}
$$

(a)

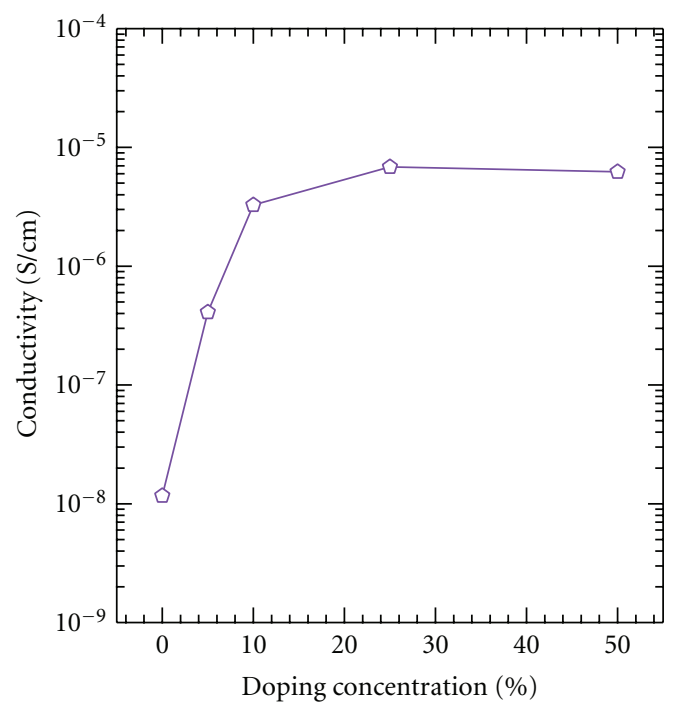

(b)

Figure 2: (a) Current density-voltage $(J-V)$ characteristics of the hole-only devices with different $\mathrm{MoO}_{3}$ concentrations (solid line: without $\mathrm{MoO}_{3}(5 \mathrm{~nm})$ layer in both electrodes; dashed line: with $\mathrm{MoO}_{3}(5 \mathrm{~nm}$ ) layer in both electrodes); (b) electrical conductivities of $\mathrm{MoO}_{3}$-doped TAPC films with different doping concentrations.

abilities with respect to the device with an undoped layer. In comparing devices with an undoped and a $5 \% \mathrm{MoO}_{3}$ doped layer, the current density of the device with the $\mathrm{MoO}_{3}$ layer $(5 \mathrm{~nm})$ in the electrode is higher than that of the device without the $\mathrm{MoO}_{3}$ layer $(5 \mathrm{~nm})$; however, the current density of the devices with doping concentrations above $10 \%$ is almost the same regardless of the insertion of the $\mathrm{MoO}_{3}$ layer $(5 \mathrm{~nm})$. This result indicates that the hole injection barrier between ITO and the $\mathrm{MoO}_{3}$-doped TAPC layer is similar to that between ITO and the $\mathrm{MoO}_{3}$ layer when the doping concentration is greater than $10 \%$. The current density of the device increases as the doping concentration increases. However, the current density of a $50 \%$ doped layer is slightly lower than that of a $25 \%$ doped layer. This result is different from those observed in the absorption spectra. This may be due to the fact that heavily doped $\mathrm{MoO}_{3}$ reduces the hole mobility of the doped film. The decrease in hole mobility has previously been observed in $\mathrm{MoO}_{3}$-doped $N^{\prime}$-diphenyl- $N, N^{\prime}$-bis (1-naphthyl) $\left(1,1^{\prime}\right.$ biphenyl)-4,4'-diamine (NPB) [18]. Figure 2(b) shows the electrical conductivities of the $\mathrm{MoO}_{3}$-doped TAPC films as a function of $\mathrm{MoO}_{3}$ doping concentration, which is derived from the ohmic regime of the $J-V$ characteristics in Figure 2(a). The electrical conductivity of $\mathrm{MoO}_{3}$-doped TAPC film increases as the $\mathrm{MoO}_{3}$ doping concentration increases. When the doping concentration is greater than $25 \%$, the $\mathrm{MoO}_{3}$-doped TAPC films exhibit similar electrical conductivities. The electrical conductivity of the undoped, $5 \%, 10 \%, 25 \%$, and $50 \% \mathrm{MoO}_{3}$-doped TAPC films is approximately $1.2 \times 10^{-8}, 4.1 \times 10^{-7}, 3.3 \times 10^{-6}, 6.9 \times$ $10^{-6}$, and $6.2 \times 10^{-6} \mathrm{~S} \cdot \mathrm{cm}^{-1}$, respectively. These values are similar to the reported values for $\mathrm{MoO}_{x}$-doped $4^{\prime}, 4^{\prime \prime}$-tri $(\mathrm{N}$ carbazolyl)triphenylamine (TCTA) or NPB [8]. The above results indicate that $\mathrm{MoO}_{3}$-doped TAPC films can be used as HTLs in OLEDs to reduce the driving voltage and to improve the power efficiency.

3.2. Phosphorescent WOLEDs. To investigate the effect of $\mathrm{MoO}_{3}$-doped TAPC layer in the OLEDs, we have fabricated WOLEDs with $\mathrm{MoO}_{3}$-doped TAPC layer. Figures 3(a)3 (c) show the chemical structure of the organic materials, device structure, and schematic energy level diagram of WOLEDs, respectively. An $\mathrm{MoO}_{3}$-doped TAPC film was used as an HTL as well as a hole injection layer (HIL) in the device. We changed the doping concentration from $5 \mathrm{vol} \%$ to $50 \mathrm{vol} \%$. To prevent exciton quenching in the EML by the dopants in the HTL, we inserted an undoped TAPC film as a buffer layer between the $\mathrm{MoO}_{3}$-doped TAPC layer and the emitting layer [19]. We used 1,3bis (9-carbazolyl)benzene $(\mathrm{mCP})$ as a host for the emitting layer and three phosphorescent dopants iridium(III) bis[4,6difluorophenyl]-pyridinato- $\left.\mathrm{N}, \mathrm{C}^{2^{\prime}}\right]$ picolinate (FIrpic) as a blue dopant, bis(2-phenylbenxothiozolato- $\left.\mathrm{N}, \mathrm{C}^{2^{\prime}}\right)$ iridium (III) (acetylacetonate) $\left(\operatorname{Ir}(\mathrm{BT})_{2}(\mathrm{acac})\right)$ as an orange dopant [20], and bis(1-phenylisoquinoline) (acetylacetonate) iridium(III) $\left(\operatorname{Ir}(\mathrm{piq})_{2}(\mathrm{acac})\right)$ as a red dopant [21]. We used tris[3-(3-pyridyl)mesityl]borane (3TPYMB) as an electron transport layer (ETL) because of its deep HOMO and high triplet energy level [22]. This electron transport material can block holes and confine triplet excitons effectively [22, 23]. Lithium fluoride $(\mathrm{LiF})$ and aluminum $(\mathrm{Al})$ were used as an electron injection layer and cathode, respectively. For comparison, we also fabricated WOLEDs with an undoped TAPC layer $(30 \mathrm{~nm})$ as an HTL and $\mathrm{MoO}_{3}(10 \mathrm{~nm})$ as an HIL instead of a $\mathrm{MoO}_{3}$-doped TAPC layer $(40 \mathrm{~nm})$. Since the WOLEDs have three emitting layers with different colors, we 

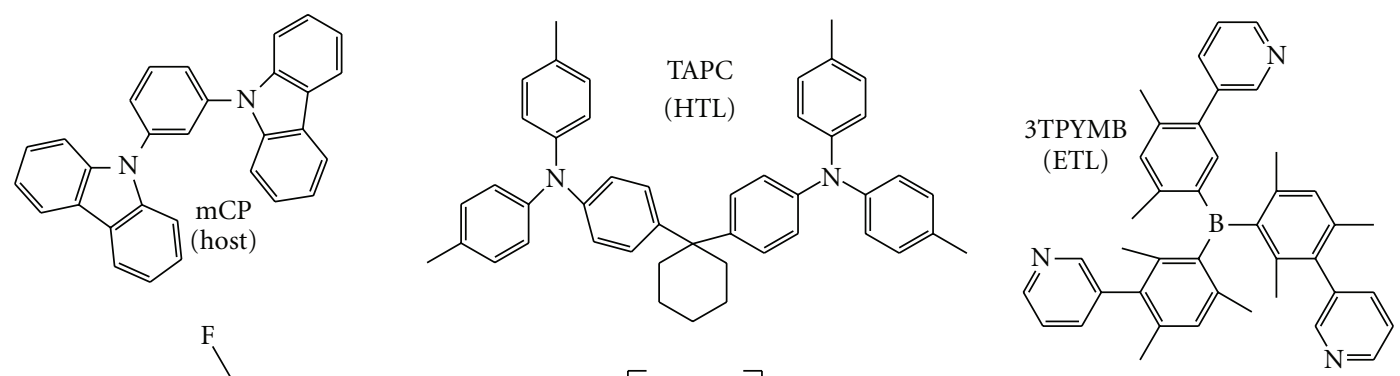

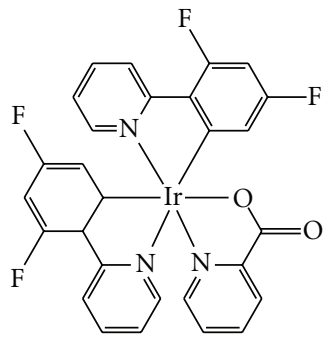

FIrpic (blue dopant)

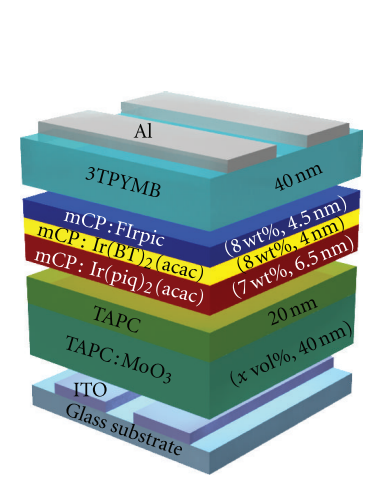

(b)

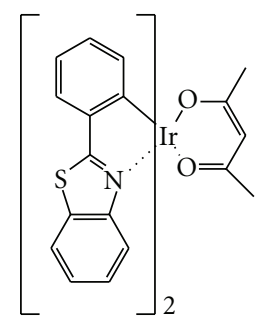

$\operatorname{Ir}(\mathrm{BT})_{2}(\mathrm{acac})$

(orange dopant)

(a)

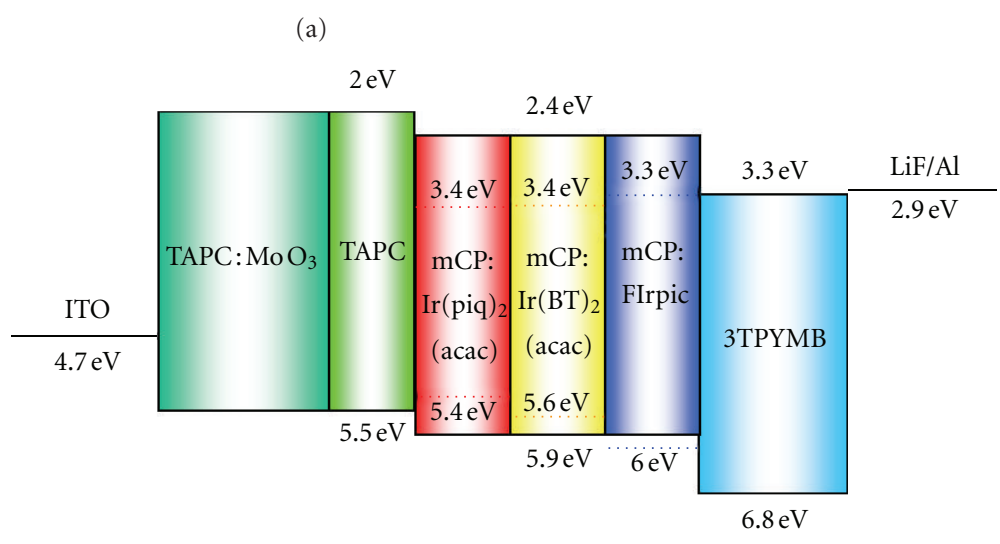

(c)

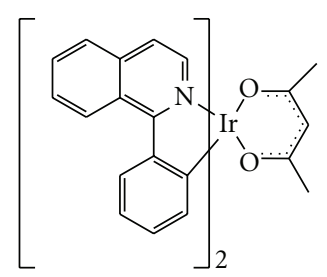

$\operatorname{Ir}(\mathrm{piq})_{2}(\mathrm{acac})$ (red dopant)

FIGURE 3: (a) Chemical structure of the organic materials, (b) device structure, and (c) schematic energy level diagram of WOLEDs.

can easily find the variation of recombination region with $\mathrm{MoO}_{3}$ doping concentrations compared with monocolor OLEDs.

Figures 4(a) and 4(b) show the $J-V$ and luminancevoltage $(L-V)$ characteristics of the devices prepared with different $\mathrm{MoO}_{3}$ doping concentrations, respectively. It is clear that the current density and luminance of the device increase significantly with the insertion of the $\mathrm{MoO}_{3}$-doped TAPC layer compared with the device with an undoped layer. For the device with $25 \%$ doping concentration, the driving voltage at $1,000 \mathrm{~cd} \cdot \mathrm{m}^{-2}, V_{1,000 \mathrm{nit}}$, is $5.6 \mathrm{~V}$, and the current density at $10 \mathrm{~V}, J_{10 \mathrm{~V}}$, is around $230 \mathrm{~mA} \cdot \mathrm{cm}^{-2}$, whereas $V_{1,000 \mathrm{nit}}$ is $6.8 \mathrm{~V}$ and $J_{10 \mathrm{~V}}$ is around $73 \mathrm{~mA} \cdot \mathrm{cm}^{-2}$ for the device with an undoped layer. This result indicates that the layer of $\mathrm{MoO}_{3}$-doped TAPC can inject and transport holes very efficiently due to the ohmic contact between ITO and the $\mathrm{MoO}_{3}$-doped TAPC layer and enhanced electrical conductivity. However, the increase in the luminance of all devices decreases in the high-current-density region as shown in the inset of Figure 4(b). The slope of $L-J$ curve decreases when the current density of the device is greater than about $20 \mathrm{~mA} \cdot \mathrm{cm}^{-2}$. As the current density of the device increases, many holes accumulate at the interface between the emitting layer and 3TPYMB because of the deep HOMO energy level of 3TPYMB and the relatively higher hole mobility of $\mathrm{mCP}$ with respect to the electron mobility [24]; the accumulated holes then disturb the radiative emission of triplet excitons. In other words, triplet-triplet (T-T) annihilation or triplet-polaron quenching may cause the decrease of the luminance in the high-current-density region [25].

Figures 5(a) and 5(b) show the power efficiency (PE) versus luminance characteristics and the $\mathrm{PE}$ and external quantum efficiency $(\mathrm{EQE})$ of the devices at $1,000 \mathrm{~cd} \cdot \mathrm{m}^{-2}$ with different $\mathrm{MoO}_{3}$ doping concentrations, respectively. The PE of the device with an $\mathrm{MoO}_{3}$-doped TAPC layer is much higher than that of the device with an undoped layer. The PE of the device with undoped, 5\%, 10\%, 25\%, and 50\% $\mathrm{MoO}_{3}$-doped layer is $9.8,11.2,11.4,11.0$, and $10.7 \mathrm{~lm} \cdot \mathrm{W}^{-1}$ at $100 \mathrm{~cd} \cdot \mathrm{m}^{-2}$, respectively. These values are comparable to the reported values for the WOLEDs with similar emitting colors which are blue, orange, and red [21]. The PE of the device 


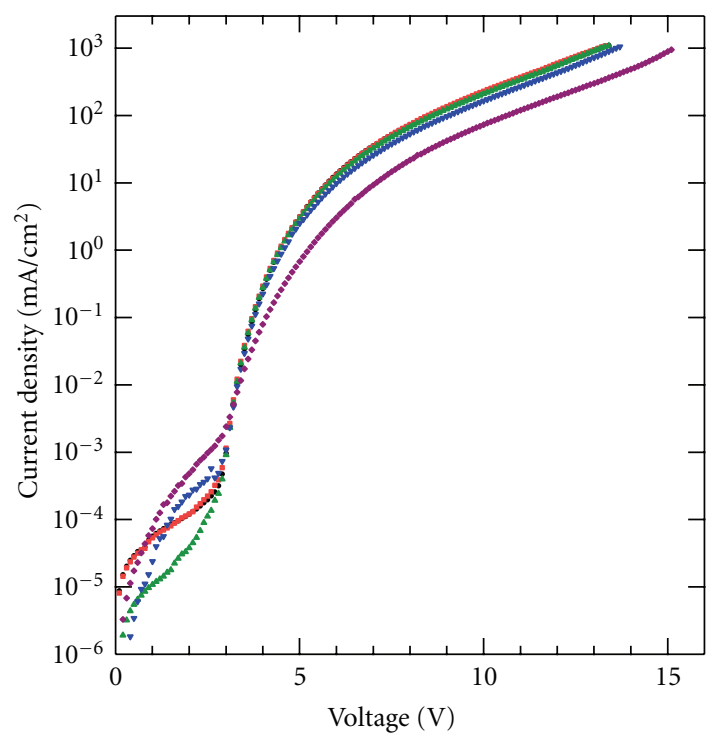

(a)

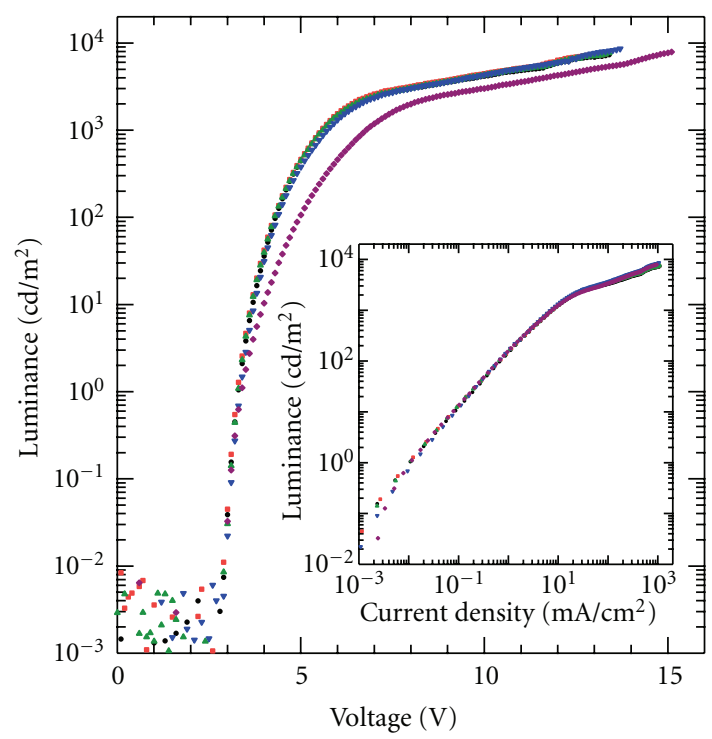

- TAPC: $\mathrm{MoO}_{3}(50 \%)$ - TAPC: $\mathrm{MoO}_{3}(25 \%)$

- TAPC: $\mathrm{MoO}_{3}(10 \%) \quad$ TAPC: $\mathrm{MoO}_{3}(5 \%)$

Undoped

(b)

Figure 4: (a) Current density-voltage $(J-V)$ and (b) luminancevoltage $(L-V)$ characteristics of WOLEDs with different $\mathrm{MoO}_{3}$ doping concentrations. Inset in (b): luminance-current density ( $L$ $J)$ characteristics from the same devices.

with a $5 \%$ doping concentration is around $7.9 \mathrm{~lm} \cdot \mathrm{W}^{-1}$ at $1,000 \mathrm{~cd} \cdot \mathrm{m}^{-2}$, which is $27.4 \%$ higher than that of the undoped device, which is around $6.2 \mathrm{~lm} \cdot \mathrm{W}^{-1}$. The $\mathrm{PE}$ of the device with a $\mathrm{MoO}_{3}$-doped TAPC layer increases up to a doping concentration of $5 \%$ and then decreases at $1,000 \mathrm{~cd} \cdot \mathrm{m}^{-2}$ as shown in Figure $5(\mathrm{~b})$. This pattern is related to the EQE variation tendency with the doping concentration. The hole mobility of TAPC is much higher than the electron mobility of 3TPYMB [23]. The electrical conductivity of TAPC increases with the $\mathrm{MoO}_{3}$ doping

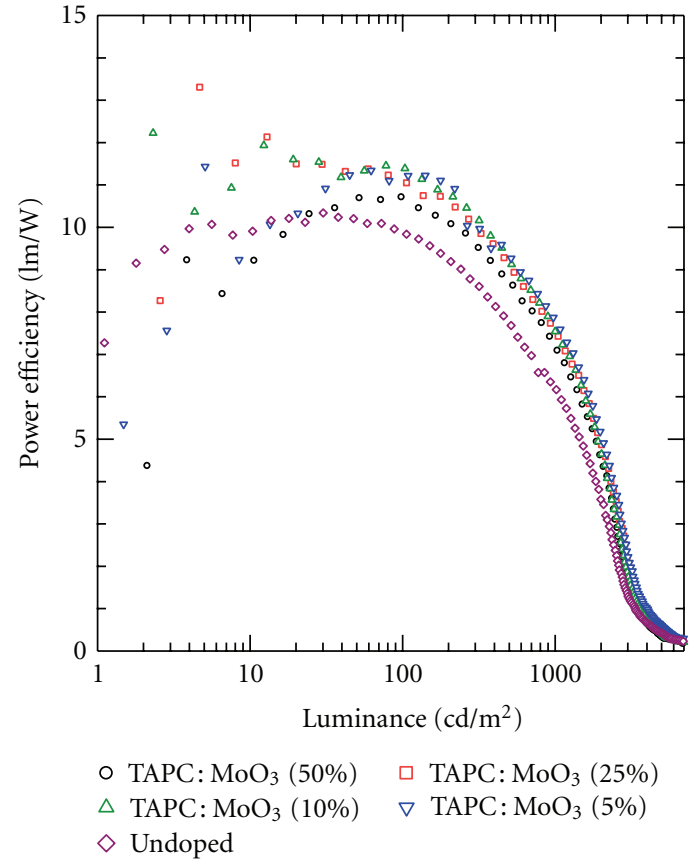

(a)

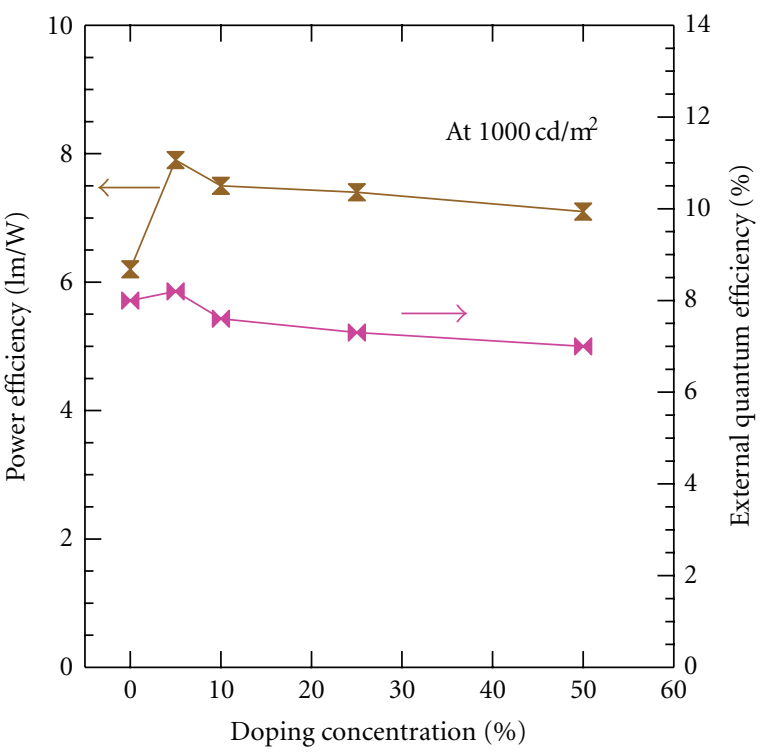

(b)

FIgURE 5: (a) Power efficiency versus luminance characteristics and (b) power efficiency and external quantum efficiency of WOLEDs at $1,000 \mathrm{~cd} \cdot \mathrm{m}^{-2}$ with different $\mathrm{MoO}_{3}$ doping concentrations.

concentration. Therefore, the hole density is much higher than the electron density in the emitting layer as the doping concentration increases, a pattern that leads to an electronhole imbalance, and, thus, the EQE decreases as the doping concentration increases. This electron-hole imbalance can be improved by employing an electron transport material with a high electron mobility or n-doped organic layer. We summarize the performance of phosphorescent WOLEDs with different $\mathrm{MoO}_{3}$ doping concentrations in Table 1. 


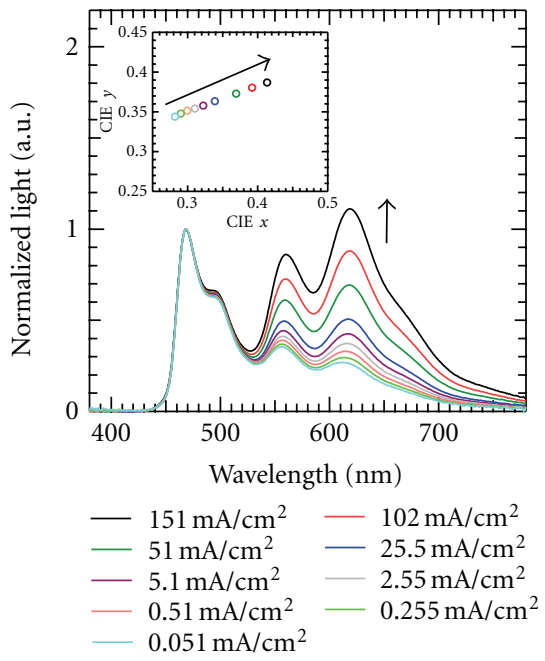

(a)

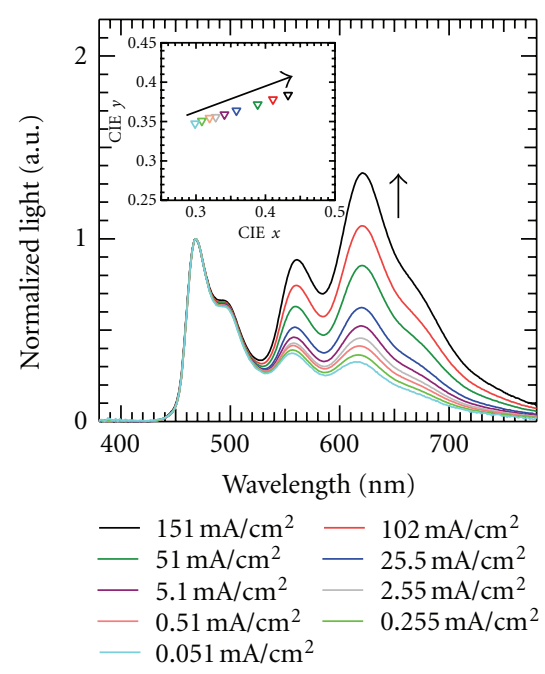

(d)

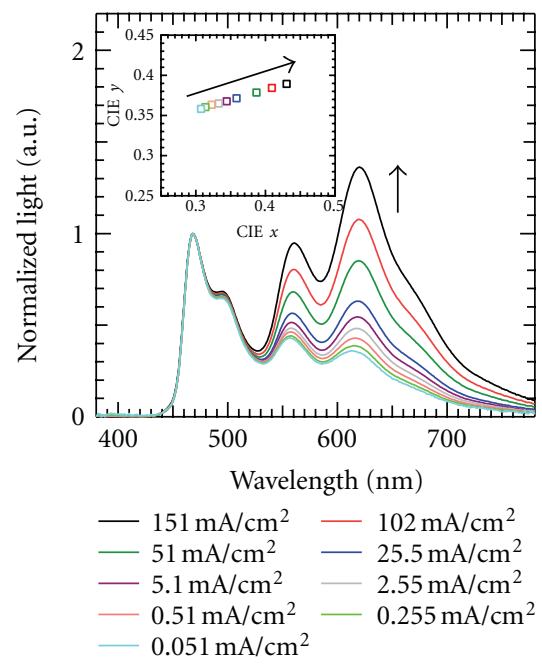

(b)

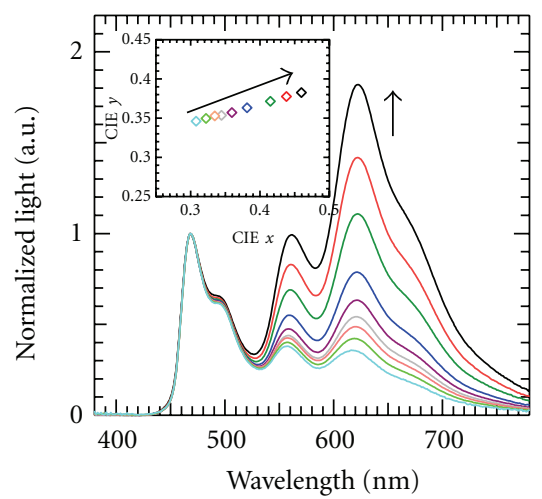

$-151 \mathrm{~mA} / \mathrm{cm}^{2}-102 \mathrm{~mA} / \mathrm{cm}^{2}$
$-51 \mathrm{~mA} / \mathrm{cm}^{2}-25.5 \mathrm{~mA} / \mathrm{cm}^{2}$
$-5.1 \mathrm{~mA} / \mathrm{cm}^{2}-2.55 \mathrm{~mA} / \mathrm{cm}^{2}$
$-0.51 \mathrm{~mA} / \mathrm{cm}^{2}-0.255 \mathrm{~mA} / \mathrm{cm}^{2}$
$-0.051 \mathrm{~mA} / \mathrm{cm}^{2}$

(e)

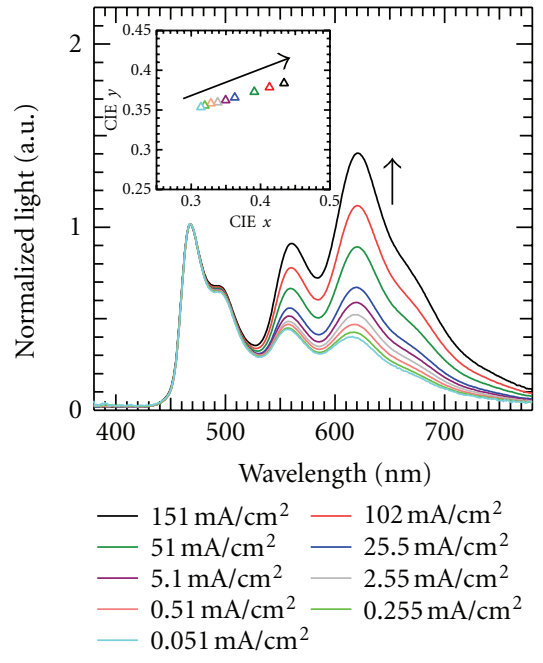

(c)

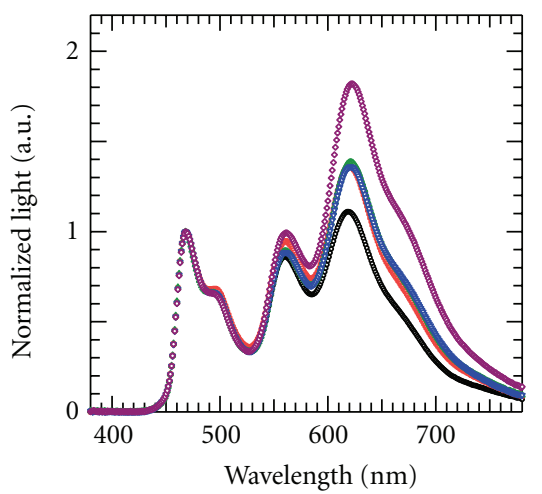

- TAPC: $\mathrm{MoO}_{3}(50 \%)$

- TAPC: $\mathrm{MoO}_{3}(25 \%)$

$\triangle$ TAPC: $\mathrm{MoO}_{3}(10 \%)$

$\checkmark$ TAPC: $\mathrm{MoO}_{3}(5 \%)$

$\diamond$ Undoped

(f)

FIgure 6: (a)-(e) Normalized EL spectra of WOLEDs with different current density at fixed doping concentrations and (f) with different $\mathrm{MoO}_{3}$ doping concentrations at the same current density $\left(J=153 \mathrm{~mA} \cdot \mathrm{cm}^{-2}\right)$. Each inset shows the corresponding CIE color coordinates. The arrows indicate the spectral and CIE color coordinates variations with increasing current density from 0.051 to $153 \mathrm{~mA} \cdot \mathrm{cm}^{-2}$.

TABle 1: Performance of the WOLEDs with different $\mathrm{MoO}_{3}$ doping concentrations.

\begin{tabular}{|c|c|c|c|c|c|c|}
\hline $\begin{array}{l}\text { Doping } \\
\text { concentration }\end{array}$ & $\begin{array}{l}\text { Current density } \\
\qquad\left(\mathrm{mA} \cdot \mathrm{cm}^{-2}\right)\end{array}$ & $\begin{array}{c}\text { Driving voltage } \mathrm{e}^{\mathrm{b}} \\
(\mathrm{V})\end{array}$ & $\begin{array}{l}\text { Max. EQE } \\
(\%)\end{array}$ & $\mathrm{PE}^{\mathrm{b}}\left(\operatorname{lm} \cdot \mathrm{W}^{-1}\right)$ & $\begin{array}{c}\text { CIE } 1931(x, y) \\
\text { chromatic } \\
\text { coordinates }^{c}\end{array}$ & $\mathrm{CRI}^{\mathrm{c}}$ \\
\hline $50 \%$ & 222 & 5.6 & 8.1 & 7.1 & $(0.4134,0.3729)$ & 85 \\
\hline $25 \%$ & 230 & 5.6 & 8.4 & 7.4 & $(0.4303,0.3893)$ & 86 \\
\hline $10 \%$ & 210 & 5.6 & 8.9 & 7.5 & $(0.4339,0.3837)$ & 84 \\
\hline $5 \%$ & 165 & 5.7 & 9.3 & 7.9 & $(0.4325,0.3837)$ & 84 \\
\hline undoped & 73 & 6.8 & 9.5 & 6.2 & $(0.4596,0.3826)$ & 84 \\
\hline
\end{tabular}

${ }^{\mathrm{a}}$ At $10 \mathrm{~V}$.

${ }^{b}$ At luminance of $1,000 \mathrm{~cd} \cdot \mathrm{m}^{-2}$.

${ }^{\mathrm{c}}$ At current density of $153 \mathrm{~mA} \cdot \mathrm{cm}^{-2}$. 


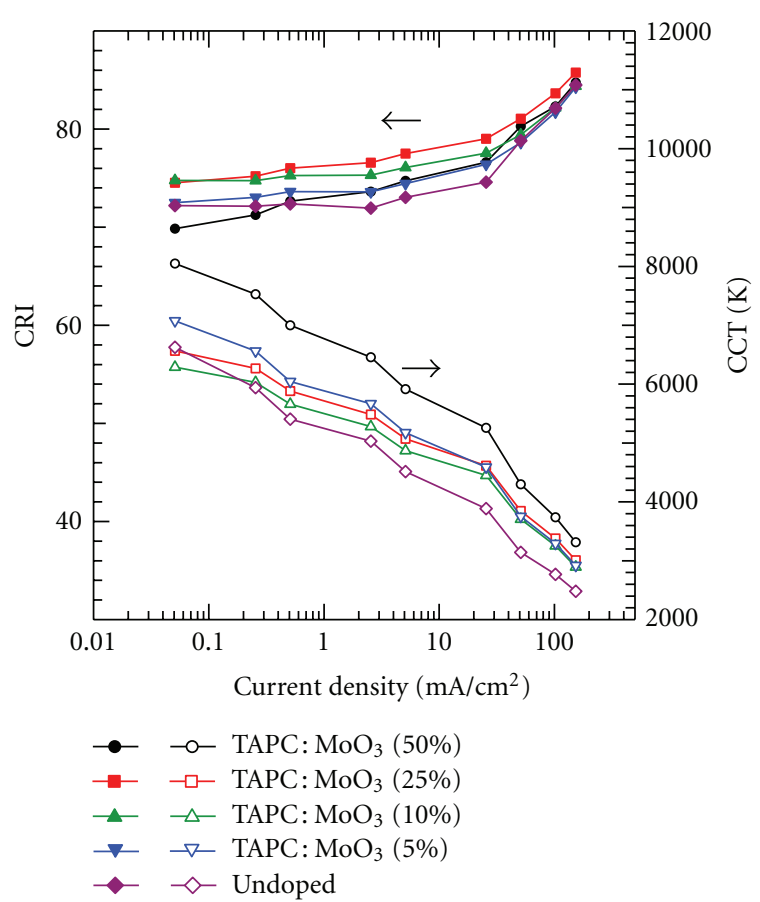

Figure 7: CRI and CCT of WOLEDs with different $\mathrm{MoO}_{3}$ doping concentrations as a function of current density.

Figures 6(a)-6(e) show the EL spectra, normalized by the main emission peak of FIrpic at $468 \mathrm{~nm}$, for WOLEDs with different $\mathrm{MoO}_{3}$ doping concentrations at various current densities. The orange $(\sim 560 \mathrm{~nm})$ and the red $(\sim 620 \mathrm{~nm})$ emission peaks of the EL spectrum increase irrespective of the $\mathrm{MoO}_{3}$ doping concentrations as the current density increases, so the CIE 1931 chromatic coordinates move to red region. The hole can be easily trapped in the red and orange emitting layer due to the deep HOMO level of $\operatorname{Ir}(\mathrm{piq})_{2}$ (acac) and $\operatorname{Ir}(\mathrm{BT})_{2}(\mathrm{acac})$ compared with that of $\mathrm{mCP}$. As the current density increases, the amounts of trapped hole increase in the red and orange emitting layer, resulting in the color shift as shown in each inset of Figures 6(a)-6(e). The CRI increases as the current density increases regardless of $\mathrm{MoO}_{3}$ doping concentrations as shown in Figure 7. All devices show high CRI which are over 84 at $J=153 \mathrm{~mA} \cdot \mathrm{cm}^{-2}$ due to obvious three emissive zones and a broad resulting spectrum. On the other hand, the CCT decreases as the current density increases because of red and orange emission increase. The ranges of CCT and CIE 1931 chromatic coordinate of the devices are from $2400 \mathrm{~K}$ to $3400 \mathrm{~K}$ and from $(0.4596,0.3826)$ to $(0.4134$, $0.3729)$, respectively, at $153 \mathrm{~mA} / \mathrm{cm}^{2}$ when the $\mathrm{MoO}_{3}$ doping concentrations change from $0 \%$ to $50 \%$. These values are comparable to the values of incandescent bulb which are $2854 \mathrm{~K}$ and $(0.448,0.408)$, respectively [5]. The higher current density than $153 \mathrm{~mA} / \mathrm{cm}^{2}$ may cause nearly red color instead of white color. We also compare the EL spectra with different $\mathrm{MoO}_{3}$ doping concentrations at the same current density of $J=153 \mathrm{~mA} \cdot \mathrm{cm}^{-2}$ as shown in Figure 6(f). As the $\mathrm{MoO}_{3}$ doping concentration increases, the intensity of the red emission peak is reduced and shifted from $623 \mathrm{~nm}$ (50\%) to $619 \mathrm{~nm}$ (undoped). This result indicates that the recombination region is gradually shifted to the cathode side as the $\mathrm{MoO}_{3}$ doping concentration increases. In other words, more holes reach the ETL side by inserting an $\mathrm{MoO}_{3}$-doped TAPC layer. In addition, the increase in absorption near $703 \mathrm{~nm}$ as the doping concentration increases as shown in Figure 1 slightly affects the decrease in the red emission of the WOLEDs.

\section{Conclusion}

We have demonstrated that an $\mathrm{MoO}_{3}$-doped TAPC layer can increase the electrical conductivity of TAPC films and improve hole injection from the ITO to the TAPC layer. Therefore, the power efficiency and driving voltage of phosphorescent WOLEDs are improved by using an $\mathrm{MoO}_{3}$ doped TAPC layer as an HTL. The WOLEDs with an $\mathrm{MoO}_{3}-$ doped TAPC layer show $1.2 \mathrm{~V}$ lower driving voltage and a power efficiency of $7.9 \mathrm{~lm} \cdot \mathrm{W}^{-1}$ at $1,000 \mathrm{~cd} \cdot \mathrm{m}^{-2}$, which is about $27.4 \%$ higher than that of a device with an undoped layer. The device structure is also simplified by introducing an $\mathrm{MoO}_{3}$-doped TAPC layer because the doped $\mathrm{MoO}_{3}$ doped TAPC layer can act as a HTL as well as a HIL. In addition, the WOLEDs show a high CRI, 86, because of clear three emissive zones and a broad resulting spectrum.

\section{Acknowledgments}

This work was financially supported by the grant from the Industrial Source Technology Development Program (KI002110) and the Industrial Strategic Technology Development Program (KI002104, Development of Fundamental Technologies for Flexible Combined-Function Organic Electronic Device) of the Ministry of Knowledge Economy (MKE) of Korea. This work was also supported in part by the Ministry of Education, Science, and Technology (MEST) through the BK21 Program.

\section{References}

[1] M. C. Gather, A. Köhnen, and K. Meerholz, "White organic light-emitting diodes," Advanced Materials, vol. 23, no. 2, pp. 233-248, 2011.

[2] K. T. Kamtekar, A. P. Monkman, and M. R. Bryce, "Recent advances in white organic light-emitting materials and devices (WOLEDS)," Advanced Materials, vol. 22, no. 5, pp. 572-582, 2010.

[3] A. Misra, P. Kumar, M. N. Kamalasanan, and S. Chandra, "White organic LEDs and their recent advancements," Semiconductor Science and Technology, vol. 21, no. 7, article R01, pp. R35-R47, 2006.

[4] D. Gupta, M. Katiyar, and Deepak, "Various approaches to white organic light emitting diodes and their recent advancements," Optical Materials, vol. 28, no. 4, pp. 295-301, 2006.

[5] B. W. D'Andrade and S. R. Forrest, "White organic lightemitting devices for solid-state lighting," Advanced Materials, vol. 16, no. 18, pp. 1585-1595, 2004. 
[6] K. Goushi, R. Kwong, J. J. Brown, H. Sasabe, and C. Adachi, "Triplet exciton confinement and unconfinement by adjacent hole-transport layers," Journal of Applied Physics, vol. 95, no. 12, pp. 7798-7802, 2004.

[7] M. Pfeiffer, K. Leo, X. Zhou et al., "Doped organic semiconductors: physics and application in light emitting diodes," Organic Electronics, vol. 4, no. 2-3, pp. 89-103, 2003.

[8] X. Qiao, J. Chen, X. Li, and D. Ma, "Observation of hole hopping via dopant in $\mathrm{MoO}_{x}$-doped organic semiconductors: mechanism analysis and application for high performance organic light-emitting devices," Journal of Applied Physics, vol. 107, no. 10, Article ID 104505, 6 pages, 2010.

[9] M. Kröger, S. Hamwi, J. Meyer, T. Riedl, W. Kowalsky, and A. Kahn, "p-type doping of organic wide band gap materials by transition metal oxides: a case-study on Molybdenum trioxide," Organic Electronicss, vol. 10, no. 5, pp. 932-938, 2009.

[10] S. Hamwi, J. Meyer, T. Winkler, T. Riedl, and W. Kowalsky, "p-type doping efficiency of $\mathrm{MoO}_{3}$ in organic hole transport materials," Applied Physics Letters, vol. 94, no. 25, Article ID 253307, 3 pages, 2009.

[11] C. I. Wu, C. T. Lin, G. R. Lee, T. Y. Cho, C. C. Wu, and T. W. $\mathrm{Pi}$, "Electronic and chemical properties of molybdenum oxide doped hole injection layers in organic light emitting diodes," Journal of Applied Physics, vol. 105, no. 3, Article ID 033717, 4 pages, 2009.

[12] J. Yun, J. Yang, Y. Hong, C. Lee, W. J. Song, and Y. J. Sung, "Low-driving-voltage, long-lifetime organic lightemitting diodes with molybdenum-oxide $\left(\mathrm{MoO}_{3}\right)$-doped hole transport layers," Journal of the Korean Physical Society, vol. 53, no. 3, pp. 1660-1664, 2008.

[13] F. Wang, X. Qiao, T. Xiong, and D. Ma, "Tungsten oxide doped $N, N^{\prime}$-di(naphthalen-1-yl)- $N, N^{\prime}$-diphenyl-benzidine as hole injection layer for high performance organic lightemitting diodes," Journal of Applied Physics, vol. 105, no. 8, Article ID 084518, 6 pages, 2009.

[14] T. Azuma et al., Method of Measuring and Specifying Colour Rendering Properties of Light Sources, Commission Internationale de l'Eclairage, 1995.

[15] J. Endo, T. Matsumoto, and J. Kido, "Organic electroluminescent devices with a vacuum-deposited Lewis-acid-doped holeinjecting layer," Japanese Journal of Applied Physics, Part 2, vol. 41, no. 3, pp. L358-L360, 2002.

[16] W. J. Shin, J. Y. Lee, J. C. Kim, T. H. Yoon, T. S. Kim, and O. K. Song, "Bulk and interface properties of molybdenum trioxide-doped hole transporting layer in organic lightemitting diodes," Organic Electronics, vol. 9, no. 3, pp. 333$338,2008$.

[17] H. Lee, S. W. Cho, K. Han et al., "The origin of the hole injection improvements at indium tin oxide/molybdenum trioxide/ $N, N^{\prime}$-bis(1-naphthyl)- $N, N^{\prime}$-diphenyl- 1, $1^{\prime}$ biphenyl- 4, 4' -diamine interfaces," Applied Physics Letters, vol. 93, no. 4, Article ID 043308, 3 pages, 2008.

[18] C. Y.H. Chan, C. M. Chow, and S. K. So, "Using transistor technique to study the effects of transition metal oxide dopants on organic charge transporters," Organic Electronics, vol. 12, no. 8, pp. 1454-1458, 2011.

[19] G. He, M. Pfeiffer, K. Leo et al., "High-efficiency and lowvoltage $\mathrm{p}-\mathrm{i}-\mathrm{n}$ electrophosphorescent organic light-emitting diodes with double-emission layers," Applied Physics Letters, vol. 85, no. 17, pp. 3911-3913, 2004.

[20] J. Lee, J. I. Lee, and H. Y. Chu, "Efficient and color stable phosphorescent white organic light-emitting devices based on an ultra wide band-gap host," Synthetic Metals, vol. 159, no. 11, pp. 991-994, 2009.

[21] P. Chen, L. Zhang, Y. Duan et al., "Efficient white organic lightemitting devices based on blue, orange, red phosphorescent dyes," Journal of Physics D, vol. 42, no. 5, Article ID 055115, 2009.

[22] D. Tanaka, T. Takeda, T. Chiba, S. Watanabe, and J. Kido, "Novel electron-transport material containing boron atom with a high triplet excited energy level," Chemistry Letters, vol. 36, no. 2, pp. 262-263, 2007.

[23] N. Chopra, J. Lee, Y. Zheng, S.-H. Eom, J. Xue, and F. So, "High efficiency blue phosphorescent organic light-emitting device," Applied Physics Letters, vol. 93, no. 14, Article ID 143307, 3 pages, 2008.

[24] C. H. Hsiao, S. W. Liu, C. T. Chen, and J. H. Lee, "Emitting layer thickness dependence of color stability in phosphorescent organic light-emitting devices," Organic Electronics, vol. 11, no. 9, pp. 1500-1506, 2010.

[25] S. Reineke, K. Walzer, and K. Leo, “Triplet-exciton quenching in organic phosphorescent light-emitting diodes with Ir-based emitters," Physical Review B, vol. 75, no. 12, Article ID 125328, 13 pages, 2007. 


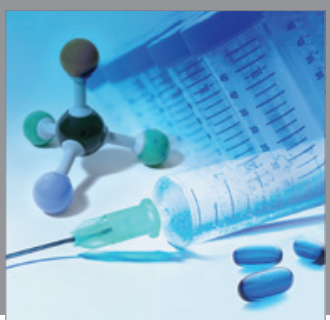

International Journal of

Medicinal Chemistry

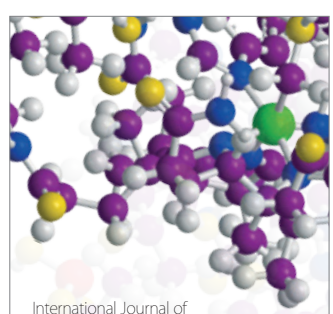

Carbohydrate Chemistry

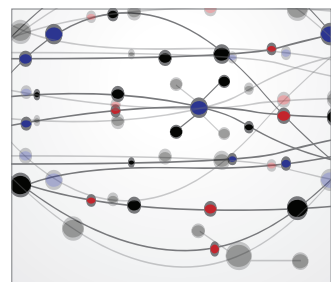

The Scientific World Journal
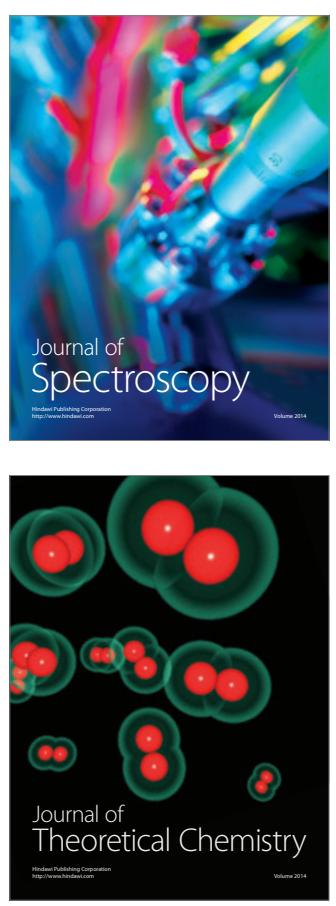
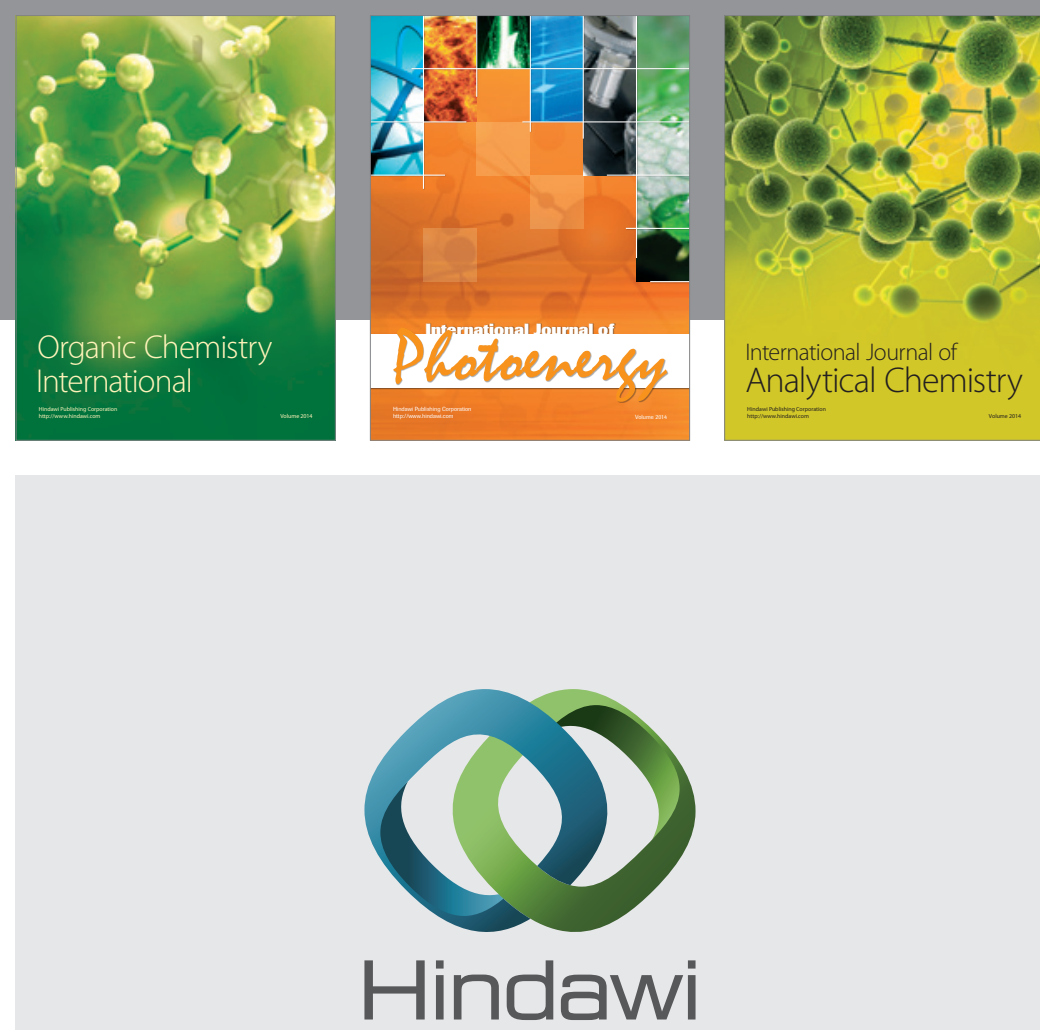

Submit your manuscripts at

http://www.hindawi.com
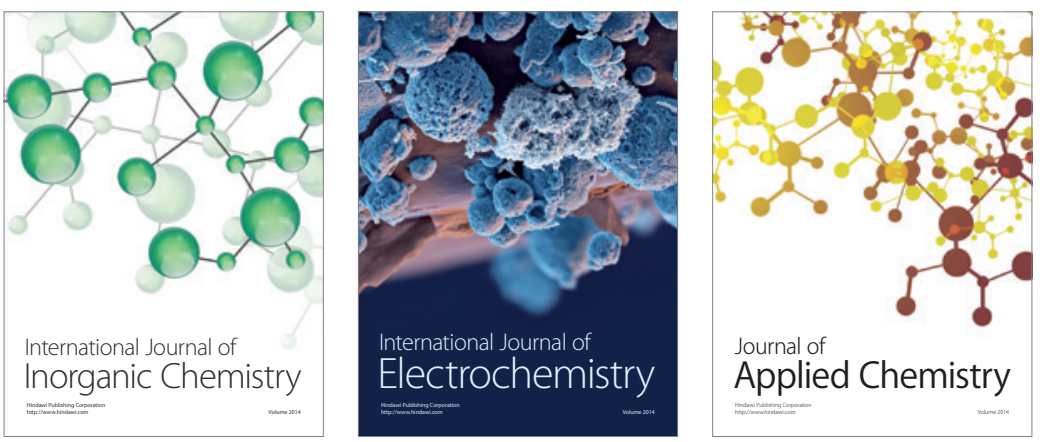

Journal of

Applied Chemistry
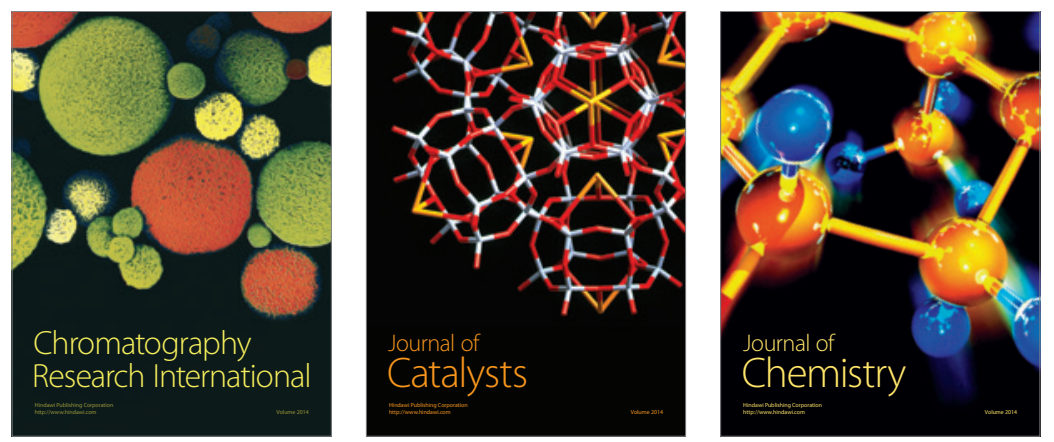
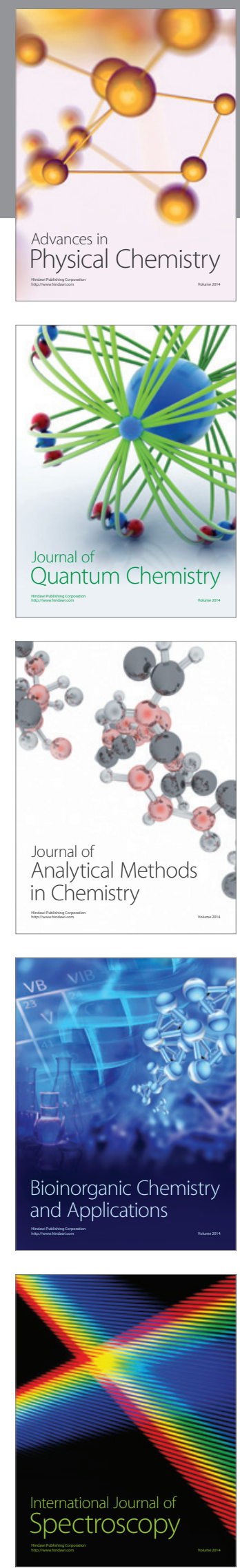